\title{
c0008 Microbiologically influenced corrosion (MIC)
}

\author{
Judit Telegdi ${ }^{1,2}$, Abdul Shaban ${ }^{1}$, Laszlo Trif ${ }^{1}$ \\ ${ }^{1}$ Hungarian Academy of Sciences, Budapest, Hungary; ${ }^{2}$ Óbuda University, Budapest, \\ Hungary
}

\section{s0010 8.1 Introduction}

p0010 Microbiologically influenced corrosion (MIC) has received increasing attention by engineers and scientists from different fields (materials and corrosion scientists and engineers, biologists, and microbiologists). MIC refers to the possibility that microorganisms are involved in the deterioration of metallic (and nonmetallic) materials. Microbial corrosion is a significant problem affecting the oil and gas and other industries. It degrades the integrity, safety, and reliability of pipeline operations and other systems. However, the mere presence of given classes of microbes associated with MIC does not indicate that MIC is occurring. Nor does showing that the presence of a given type of microorganisms establishes a cause-and-effect relationship between the bacteria and metal dissolution. For MIC to occur, water presence, even at very low amounts, is necessary [1-4].

p0015 The last decade revealed that not only the sulfate-reducing bacteria (SRB) are responsible for MIC but also several other microbes, e.g., the acid producers, iron oxidizers, and general aerobic bacteria [1]. MIC is rarely associated with one single mechanism or one single species of microorganisms. In addition to SRB many microorganisms occurring in natural environments are also considered corrosion-causing microbes, including methanogens, sulfur-oxidizing bacteria (SOB), acid-producing bacteria (APB), ironoxidizing bacteria (IOB), iron-reducing bacteria (IRB), and manganese-oxidizing bacteria (MOB). Each of these physiological groups of microorganisms may contain hundreds of individual species. Each group of bacteria or an individual species of bacteria alone can influence metal corrosion; however, severe MIC in a natural environment is always caused by microbial communities containing many different types of microbes.

p0020 For better understanding of MIC and its threats on pipelines and other structures, it is essential to learn more about how microbes influence metallic corrosion, to identify their presence and existence, and to monitor their destructive activities. MIC is not a new type of corrosion, but it involves microorganisms that, by their presence and active, aggressive metabolites and exopolymeric substances (EPS) (produced by microorganisms and composed mainly of polysaccharides) degrade materials, especially metals. The metabolic products (e.g., sulfide, organic acids) alter the interface chemistry resulting in increased corrosion rate and, together with the EPS, on the metal surface cause $\mathrm{pH}$ and dissolved oxygen gradients that lead first to localized (pitting and crevice) corrosion, which if remains unmitigated, will lead to metal wall perforations [4-6]. 
(a)

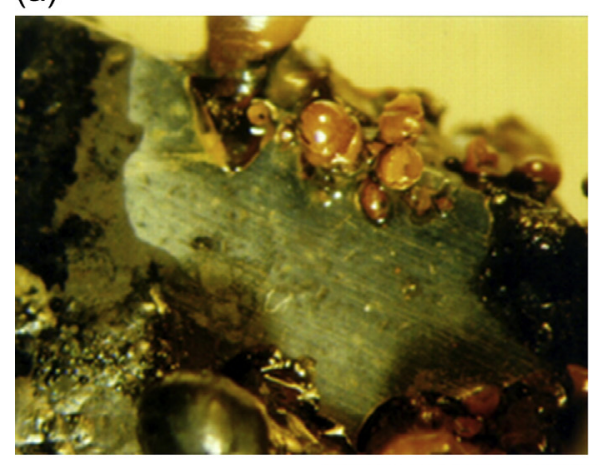

(b)

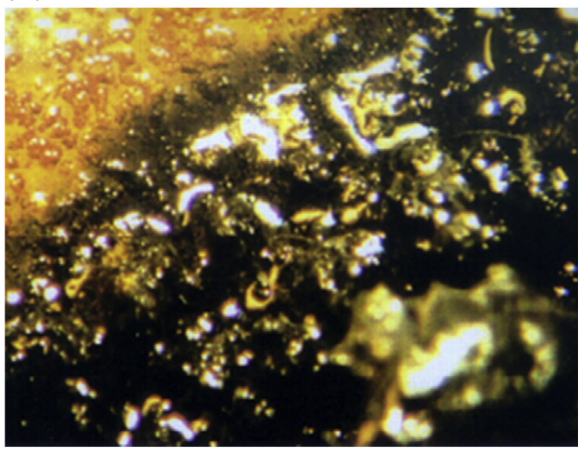

(c)

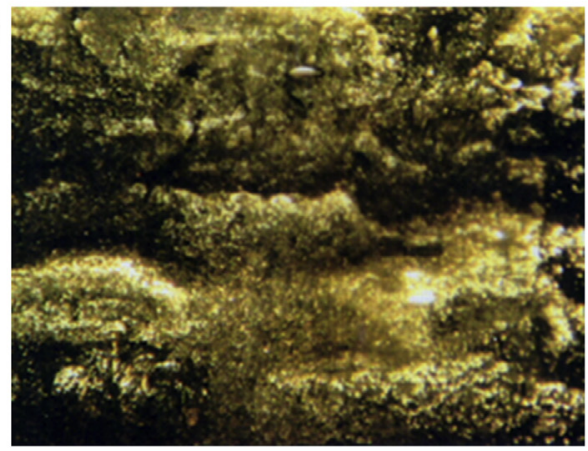

f0010 Figure 8.1 Photos of carbon steel surfaces modified in 3 months by microorganisms of mixed population. (a) Tubercles caused by aerobic iron oxidizer microbes; (b) shiny, blackish biofilm produced by anaerobic Desulfovibrios; (c) significantly roughened metal surface beneath the blackish deposition. (Magnification: 10×.)

p0025 Hydrocarbons are an excellent carbon source for a wide variety of microbes in all three forms of life (bacteria, archaea, and eucarya) that are responsible for MIC. Some microorganisms that produce hydrogen sulfide $\left(\mathrm{H}_{2} \mathrm{~S}\right)$ as a byproduct can cause severe problems in the gas and petroleum industry [7].

p0030 In all cases to confirm MIC, it is essential to document the presence of corrosionrelevant microorganisms. Fig. 8.1 (a-c) shows images of carbon steel coupon surfaces modified in 3 months by microorganisms of mixed population. Fig. 8.1(a) shows tubercles on the metal surface deteriorated by aerobic iron-oxidizing microbes; on Fig. 8.1(b), a shiny, blackish biofilm produced by anaerobic Desulfovibrios is observable; and Fig. 8.1(c) shows the metal surface beneath the blackish biofilm roughened by the presence of microbial activity.

\section{s0015 8.2 Microorganisms present in the oil and gas}

p0035 Microorganisms are present everywhere (soil, water and air) and can grow and reproduce at very rapid rates. Some microorganisms that are present in the oil and gas fields 
can cause problems, directly or indirectly, that can lead to significant economic losses and operational failures for the oil and gas industry $[8,9]$.

p0040 A great deal of research was devoted to study the effects of sulfide production by microbes in oil and gas fields. Sulfide production by these microbes can cause many problems such as reservoir souring (due to $\mathrm{H}_{2} \mathrm{~S}$ ), reservoir plugging (due to poorly soluble products), reduced product quality, and metallic corrosion $[9,10]$.

p0045 Some microorganisms possess extreme tolerance to severe environments such as low (acidic) and high (alkaline) $\mathrm{pH}$ values, as well as low and high pressure and temperature ranges [11]. They can not only withstand such harsh circumstances but also generate some conditions to create aggressive environments, which will promote direct or indirect effect on metal deterioration.

p0050 As early as 1920s, microbiologists isolated SRB in oil environments [12]. There are several dozens of bacteria that cause MIC on carbon and stainless steels, copper, and aluminum alloys (tanks, pipelines, flanged joints) in humid or aqueous environments.

\section{s0020 8.2.1 Microorganisms associated with microbiologically influenced corrosion}

p0055 The role of microorganisms in the deterioration and failure of materials can be classified into biofouling, biodeterioration, and biocorrosion. Chemolithotrophic bacteria attain their energy from the oxidation of noncarbon compounds (inorganic) i.e., from the stored energy in chemical compounds, which is utilized by oxidation process. Sulfur, ammonium ion $\left(\mathrm{NH}^{4+}\right)$, and ferrous iron $\left(\mathrm{Fe}^{2+}\right)$ are just some examples of inorganic compounds that are utilized by these types of bacteria [13]. Chemolithotrophic bacteria that are associated with MIC in the oil and gas industry are summarized in the next sections.

\section{s0025 8.2.1.1 Methanogens}

p0060 Oil reservoir methanogenic microorganisms metabolize $\mathrm{H}_{2}, \mathrm{CO}_{2}$, acetate, methylamines etc. with production of methane [13].

\section{s0030 8.2.1.2 Sulfate-reducing bacteria}

p0065 These bacteria were the first microorganisms recovered from oil fields [14]. Microorganisms belonging to this group have four subgroups: proteobacteria (Desulfovibrionales, Desulfobacterales, Syntrophobacterales), firmicutes, thermodesulfobacteria, and archea.

p0070 Seawaters, which contain sulfate ions, are widely used in enhanced oil recovery operations. SRB are anaerobes that obtain their growth energy by oxidizing organic compounds or molecular hydrogen $\left(\mathrm{H}_{2}\right)$ while reducing sulfate $\left(\mathrm{SO}_{4}^{2-}\right)$ to hydrogen sulfide $\left(\mathrm{H}_{2} \mathrm{~S}\right)$ [15]. In other words, SRB in an anaerobic respiration, use sulfate instead of oxygen, and oxidize organic substances to organic acids and $\mathrm{CO}_{2}$, by the reduction of sulfate to sulfide [15]. The presence of $\mathrm{H}_{2} \mathrm{~S}$ causes serious problems by reacting with metal (mainly iron) ions and producing ferrous sulfides (FeS), which are poorly 
soluble and, together with slime, cause dark-colored sludge that hinders oil flow [16]. In the oil and gas industry, carbon steels are the bulk material of choice, and the presence of black by-products (FeS) on the metal surface coupled with positive analysis of SRB microbes in the corrosion product is a strong indication of MIC due to SRB.

p0075 Many species of SRB from different parts of the world have been identified. They might slightly differ in their morphology (appearance) or in the energy source for their metabolism [17]. Some SRB bacteria can use both elemental sulfur and sulfate as electron acceptors. Common SRB include the genera Desulfovibrionales, Desulfosporosinus, Desulfotomaculum, Syntrophobacterales, Desulfosporomusa, and Desulfobacterales $[16,17]$. Thermodesulfovibrio sulfate-reducing species are also found as a member of the Nitrospirae phylum. At elevated temperatures, there exist two phyla of thermophilic SRB: Thermodesulfobacteria and Thermodesulfobium. Three genera of archaea Archaeoglobus, Thermocladium, and Caldivirga, which can reduce sulfate, are found in oil deposits [18].

p0080 As mentioned earlier, the damaging activities of SRB are of alarming concern to many industrial operations, specifically oil and gas industries that are seriously affected by the sulfide produced by SRB. Biogenic sulfide production causes health and safety complications, environmental hazards, and huge economic losses due to corrosion of equipment and reservoir souring.

p0085 SRB influence on the corrosion of steels can be elucidated mainly by two scenarios [11,19]:

u0010 - Chemical MIC (CMIC) of iron by hydrogen sulfide from microbial sulfate reduction occurs with "natural" organic substrates;

u0015 - SRB corrode iron by direct utilization of the metal itself. This always occurs via direct electron uptake and in only a limited number of recently discovered SRB strains. Until now, such electrical MIC (EMIC) is assumed to be widespread and of considerable technical relevance.

p0100 CMIC and EMIC are the likely primary processes that drive iron corrosion in sulfate-containing anoxic environments.

p0105 The major cause responsible for biocorrosion is attributed to SRB ability to perform dissimilatory reduction of sulfur compounds, such as sulfate, sulfite, and thiosulfate into sulfides. Some species from the Desulfovibrio genus (Desulfovibrio desulfuricans, as an example) can utilize nitrate as alternative respiratory substrate [20].

p0110 The formation of massive biofilms on metal surfaces further promotes corrosion of oil and gas pipelines [21]. Fig 8.2 presents atomic force microscopy (AFM) images of D. desulfuricans cells, where Fig. 8.2(a) shows several microbes scattered on the metal surface, and Fig. 8.2(b) shows the inner structure of the cell membrane visualized at nanometer scale.

\section{s0035 8.2.1.3 Iron- and manganese-oxidizing bacteria}

p0115 Iron bacteria may be described as a group of aerobic bacteria, which can metabolize by utilizing the oxidation of ferrous and/or manganous ions. The colored deposits of these microorganisms are due to the products of ferric (brown) and/or manganese (pink) salts 


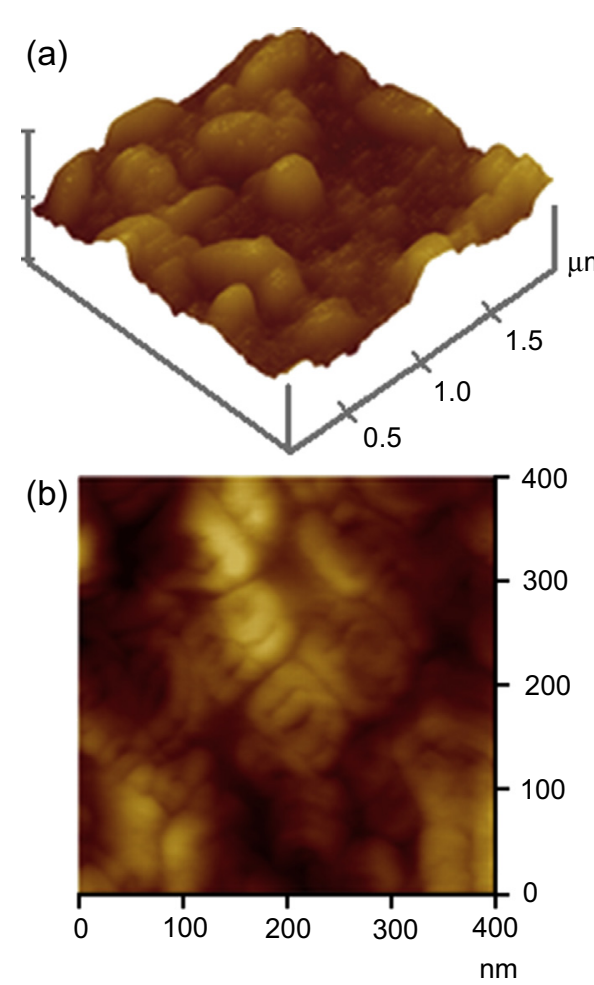

f0015 Figure 8.2 Atomic force microscopy images on Desulfovibrio desulfuricans cells; (a) several microbes scattered on iron surface; (b) details of cell membrane morphology visualized at nanometer scale.

(usually hydroxides). It has been speculated that the biofilms of iron- and manganeseoxidizing bacteria have a direct effect on the chemistry of the passive films of metals by attachment and deposit metal oxides on the surfaces. These oxides tend to shift the corrosion potential of the passive metals in the noble direction, causing an increase in corrosion potential, which may initiate localized forms of corrosion of passive metals [22].

p0120 IOB, such as Gallionella, Sphaerotilus, Leptothrix, and Crenothrix, which are often identified by their distinctive morphologies, such as the extracellular twisted ribbonlike stalks formed by Gallionella ferruginea, oxidize the ferrous iron $\left(\mathrm{Fe}^{2+}\right.$, a soluble form) to ferric iron $\left(\mathrm{Fe}^{3+}\right.$, an insoluble iron compound e.g., $\left.\mathrm{Fe}(\mathrm{OH})_{3}\right)$ [22]. The iron and manganese bacteria, by oxidizing ferrous to ferric ion form, thus produce extremely aggressive ferric chlorides (very low local $\mathrm{pH}$ value: $\mathrm{pH} \cong 1$ ), which causes pits on surfaces of both carbon steel and austenitic stainless steel in particular [23].

\section{s0040 8.2.1.4 Iron-reducing bacteria}

p0125 Their importance is overshadowed by the IOB although they also play significant role in MIC. In cases when IRB are together with SRB, carbon steel metal samples will be 
more severely damaged than in abiotic environments [24,25]. Several types of microorganisms (bacteria), including those from the genera Pseudomonas and Shewanella, have the ability to reduce manganese and/or iron oxides, which also influence corrosion reactions [3].

\section{s0045 8.2.1.5 Pseudomonas aeruginosa}

p0130 This Gram-negative bacterium is widely scattered in the environment and also plays an important role in the initiation of MIC in oil and gas industry. The biofilm formation by Pseudomonas aeruginosa was revealed to go through several stages: In stage I, planktonic bacteria initiate attachment to an abiotic surface formed from mainly organic components of the environment; this adhesion becomes irreversible in stage II, stage III corresponds to microcolony development, and stage IV corresponds to biofilm maturation and growth of the three-dimensional community. Finally, dispersion occurs in stage $\mathrm{V}$ and planktonic bacteria that are released from the biofilm to colonize other sites [3].

\section{s0050 8.2.1.6 Sulfur-oxidizing bacteria}

p0135 SOB are aerobes that gain energy by oxidation of the reduced sulfur compound [e.g., hydrogen sulfide $\left(\mathrm{H}_{2} \mathrm{~S}\right)$ ] into elemental sulfur $\left(\mathrm{S}^{0}\right)$ by partial oxidation, or sulfate $\left(\mathrm{SO}_{4}^{2-}\right)$, which in water forms sulfuric acid $\left(\mathrm{H}_{2} \mathrm{SO}_{4}\right)$, as well as into thiosulfate ions [26]. Beggiatoa and Paracoccus are two classical examples of SOB.

p0140 Aerobic sulfur-oxidizing prokaryotes belong to genera such as Acidianus, Acidithiobacillus, Aquaspirillum, Aquifex, Bacillus, Beggiatoa, Methylobacterium, Paracoccus, Pseudomonas, Starkeya, Sulfolobus, Thermithiobacillus, Thiobacillus, Thiothrix and Xanthobacter [27].

p0145 The most investigated genera of SOB (Thiobacillus, Sulfolobus, Thermothrix, Beggiatoa, and Thiothrix [28]), for the biological oxidation of sulfides are chemolithotrophic types. Thiobacillus ferrooxidans, an acidophile, (active in the $\mathrm{pH}$ range of $1.0-2.5)$ and also a thermophile [prefer temperatures of $45-50^{\circ} \mathrm{C}\left(113-122^{\circ} \mathrm{F}\right)$ ] oxidize iron- and sulfur-containing minerals [29]. SOB also causes the biodeterioration of concrete sewers, which takes place when microorganisms living in biofilm formed on unsubmerged sections of concrete excrete sulfuric acid, which is deleterious to the concrete [28].

\section{s0055 8.2.1.7 Slime-former bacteria}

p0150 The slime formers can exist in the presence or absence of oxygen and produce a variety of extracellular mats of high-density slime that will cover partly of fully solid surfaces. Their primary unfavorable effects are the protection of anaerobes (like SRB) and aerobes (iron/manganese/sulfur oxidizers) and the removal of metal ions derived from the metal surface, and furthermore, massive pore plugging occurs inside pipelines [30]. As the formation of biofilm/biomass matures, aerobic bacteria consume oxygen, producing metabolic by-products that are nutrient for anaerobes, and these processes create real anaerobic environments underneath the biofilm. 


\section{s0060 8.2.1.8 Acid-producing bacteria}

p0155 One of the most corrosive metabolites generated by microbes is acids as byproducts of APB that can produce organic (acetic and butyric acids) and inorganic acids (e.g., sulfuric acid) as well as nutrients for other species (e.g., fatty acids that are used by SRB). Basically, the APB could be regarded as creating conditions for increased aggressive activities by the SRB, consuming the fatty acids produced by the APB.

p0160 The APB have now been documented as a possible major cause of corrosion, mainly because of their fermentative activities that will cause the local $\mathrm{pH}$, mainly in the biofilms, to drop into the acidic range [31].

p0165 Inorganic acids, produced by microbes, are nitric acid $\left(\mathrm{HNO}_{3}\right)$, sulfurous acid $\left(\mathrm{H}_{2} \mathrm{SO}_{3}\right)$, sulfuric acid $\left(\mathrm{H}_{2} \mathrm{SO}_{4}\right)$, nitrous acid $\left(\mathrm{HNO}_{2}\right)$ and carbonic acid $\left(\mathrm{H}_{2} \mathrm{CO}_{3}\right)$.

p0170 Sulfurous acid and sulfuric acid are mainly released by bacteria of the genera Thiobacillus. Other bacteria, such as Thiothrix and Beggiatoa spp., as well as some fungi (e.g., Aureobasidium pullulans), also produce these acids [16,32].

p0175 The focal problem in sulfuric and nitric acid corrosion is the fact that the resultant salts are water soluble and, therefore, a formation of a protective corrosion product layer is not probable. Moreover, because of the decrease in $\mathrm{pH}$, protective deposits formed on the surface, e.g., calcium carbonate can easily dissolve into the liquid [31].

p0180 AFM images of a corroded iron surface (Fig. 8.3(a) and (b)) clearly show the fingerprints of the acid producer Thiomonas intermedia cells, and the sectional analysis proves the depth of pits on the coupon surface etched by the acid metabolites (more than $370 \mathrm{~nm}$ in 1 day!).

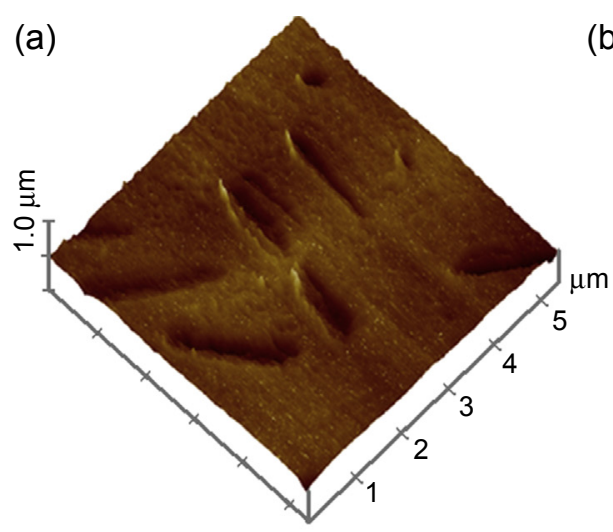

(b)

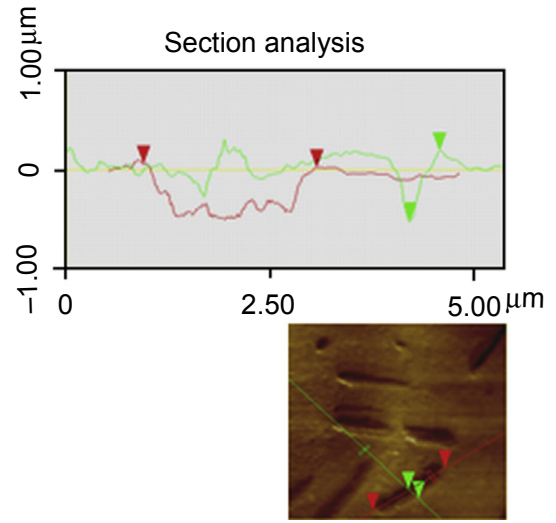

f0020 Figure 8.3 Atomic force microscopy images of iron surface after 1-day-long immersion in broth inoculated with Thiomonas intermedia. (a) Two-dimensional topographic image, which shows the fingerprints of microorganisms within the biofilm; (b) sectional analysis of pit depth formed on the coupon surface. 


\section{s0065 8.3 Classification of microorganisms}

p0185 Taxonomy, the science of classifying organisms, consists of classifying new or existing organisms.

p0190 Microorganisms are generally classified as prokaryotes or eukaryotes. A prokaryote cell has no nucleus and it multiplies by fission. On the other hand, the eukaryote organism contains true nuclei and its division is by mitosis. All organisms are composed of eukaryotic cells, except bacteria. There are examples of eukaryotic microorganisms, including fungi, algae, and protozoa, that can take part in MIC, and prokaryotic microorganisms include the bacteria and blue-green bacteria, which are the permanent participants in MIC.

p0195 Microorganisms can also be classified according to three types of characterization: morphology, physiology, and, genetic [32].

\section{s0070 8.3.1 Classification based on oxygen demand}

p0200 Oxygen utilization by bacteria suggests the mechanism used by them, to fulfill their energy requirements. On the basis of oxygen demands, bacteria can be classified into the following different categories [32]:

u0020 - Obligate anaerobes: They are harmed by the presence of oxygen hindering their growth.

u0025 - Aerotolerant organisms: They cannot use oxygen for growth, but can tolerate its presence.

u0030 - Facultative anaerobes: That can grow without oxygen but use oxygen if it is present.

u0035 - Obligate aerobes: They need oxygen to grow; in cellular respiration these microorganisms use oxygen for oxidation of substrates such as sugars and fats when energy is generated.

u0040 - Facultative aerobes: They use oxygen but also have anaerobic methods of energy production.

u0045 - Microaerophiles: Oxygen is required for energy production, but under atmospheric oxygen they are destroyed.

u0050 - Aerotolerantes: They do not use oxygen directly, but the presence of oxygen does not harm them.

\section{s0075 8.3.2 Classification of microorganisms based on energy and carbon requirement}

u0055 - Chemotrophs (respiration): They respire molecular oxygen as a terminal electron acceptor (aerobic respiration); in addition, they use nitrate (anaerobic respiration). An example of this group is methane producers.

u0060 - Chemotrophs (fermentation): The energy is derived from phosphorylation.

u0065 - Chemolithoautotrophs obtain energy though oxidation of inorganic compounds and from $\mathrm{CO}_{2}$ (sulfur and IOB, nitrifying bacteria).

u0070 - Phototrophs: They gain energy by photophosphorylation; there are both oxygen-evolving species and non-oxygen-evolving species.

u0075 - Carbon: The most important component in all living things.

u0080 - Heterotrophs: They assimilate organic compounds for their carbon needs.

u0085 - Autotrophs: They utilize carbon dioxide.

u0090 - Chemoheterotrophs, also chemoorganotrophs: Generally the organotrophs use variety of organic compounds as both carbon and energy source; a common sugar they use is glucose; and adenosine triphosphate (ATP) is generated by either substrate-level or oxidative phosphorylation. 
u0095 - Chemoautotrophs, also chemolithotrophs: They are lithotrophs; the ATP is generated by oxidative phosphorylation;

u0100 • Myxotrophs: They are "chemolithotrophic heterotrophs" using carbon dioxide;

$\mathrm{u} 0105$ - Photoheterotrophs and photoautotrophs: They utilize light as energy source and $\mathrm{CO}_{2}$ as carbon source.

\section{s0080 8.3.3 Classification of microorganisms according to taxonomic hierarchy}

p0300 Taxonomy classifies new and existing organisms. The hierarchy is the following: domain-kingdom-phylum-class-order-family-genus-species-strains.

p0305 The most widely employed methods for classifying microbes are the following:

o0010 1. morphological characteristics,

o0015 2. differential staining,

o0020 3. biochemical testing, DNA fingerprinting of DNA base composition, and;

o0025 4. polymerase chain reaction and DNA chips [33,34].

\section{s0085 8.4 Biofilms: why do microbes like to live in biofilms?}

p0330 Traditional understanding of MIC involves the formation of biofilm that provides a niche for corrosive microbes to grow and proliferate.

p0335 Microorganisms live either in planktonic or sessile form. From the point of view of corrosion, the planktonic microorganisms are less dangerous than those that are embedded in thinner or thicker deposits. In aqueous environments, microbes adhere to solid surfaces and prefer to exist in sessile form (better and safer living conditions), and they form biofilms, where metal degradation takes place underneath.

p0340 The microbial cell walls-the planktonic ones too! - are surrounded by EPS that consist mainly of polysaccharides, but peptides, nucleotides, and other components are also represented in them. It has a sticky nature, which allows the adhesion of microorganisms to solids.

p0345 The accumulation of microorganisms on metals results in biofilms that create different microenvironments. The thin films alter the solid surface properties (e.g., wettability, electrostatic charge), which lead to colonization of microbes. The biofilm is not necessarily uniform in time and place as well as in $\mathrm{pH}$, and in dissolved chemicals and oxygen concentration [35].

p0350 The first step in biofilm formation is the development of a conditional layer on a solid surface, which consists of organic compounds and inorganic ions from the liquid environment. The accumulation of microorganisms starts with reversible and later irreversible adhesion of microbes, which is enhanced by the EPS layer (that covers the cells and is a part of the conditional film). In time, more and more microbes adhere to the layer. In a shorter (several minutes) or longer (some hours) time, further adhesion, as well as EPS production and microbial growth, results in a thick, gelatinous biofilm that mainly consists of water, organisms of different species, and other components from the environment. We should keep in mind that the biofilm is a dynamic system with transport processes and chemical reactions within the biofilm; there 
is a gradient of $\mathrm{pH}$ value, ions, and microbes. The number of anaerobic cells will increase nearer to the solid surface. In contrast, the aerobes have higher cell number near the upper part of the biofilm. The main metabolite of the anaerobes is the $\mathrm{H}_{2} \mathrm{~S}$ formed from sulfate ions. This can form an insoluble black precipitate with the $\mathrm{Fe}^{2+}$ ion. This is the time when corrosion pit formation initiates by the activity of the anaerobes and the presence of FeS. The other important reaction is the oxidation of sulfide ions to sulfate ones.

p0355 Biofilm formation involves the participation of different types of microorganisms. Thus, their coherent coexistence is essential for their survival [36].

p0360 One should keep in mind that the biofilm not only protects the cells from the external environment and lets them live under safe conditions but beneath the nanolayer it also starts the deterioration of metals, and in the course of time pitting corrosion grows, which if left unmitigated, can lead to pinhole and leaks.

p0365 The tendency of microorganisms to adhere to solid surfaces can be evaluated by different approaches, such as interaction energy, thermodynamics, DLVO (Derjagin, Landau, Verwey, Overbeek), and extended DLVO theory. These methods are based on long-range and short-range interaction forces between bacteria and surfaces, by surface energy approach and the physical and chemical interactions between the solid surface, and the biofilm should be taken into consideration too [37-44]. A schematic diagram of the biofilm development, illustrated by AFM images taken at different time intervals, is shown in Fig. 8.4.

p0370 Factors that affect the biofilm development and play important role in its formation are the following:

o0030 1. Surface properties: roughness, polarization, oxide coverage, chemical composition such as $\mathrm{pH}$, medium concentration, organic and inorganic strength; all these factors have significant impact on bacterial attachment and biofilm development.

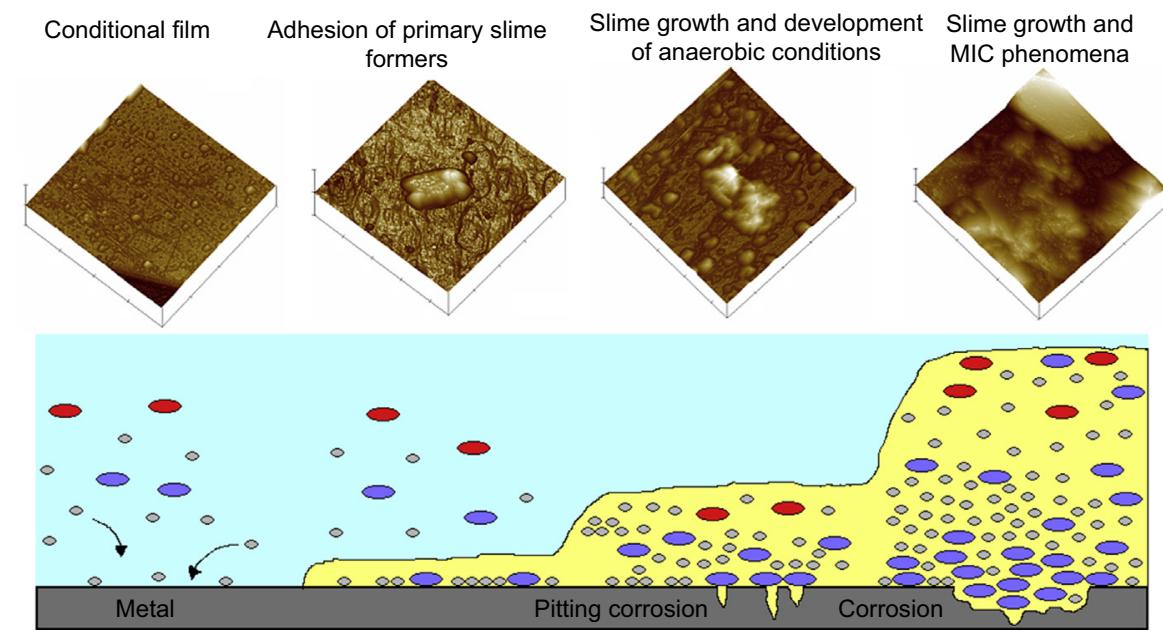

f0025 Figure 8.4 Biofilm step-by-step formation as illustrated by atomic force microscopy images. $M I C$, microbiologically influenced corrosion. 
o0035 2. Bacterial medium characteristics: the microbial cells-with some exceptions - are negatively charged at neutral $\mathrm{pH}$. The attachment of some corrosion-relevant bacteria (D. desulfuricans, Desulfovibrio singaporenus, Pseudomonas) to iron alloy surfaces shows the highest adhesion forces at $\mathrm{pH}$ values that are close to the isoelectric points of bacteria are zero potential.

p0385 Biofouling is a progression of the biofilm formation. Once microorganisms form a thick gelatinous layer, macroorganisms that are present in the media (e.g., mussels, alga, barnacles) can accumulate on the top of the layer and, together with other inorganic insoluble chemicals (precipitates of corrosion products), form a massive, welladhered biodeposit that also can plug pipes, decrease the heat exchange, and the debase the economic function/efficacy [45] as can be seen in Fig. 8.5(a).

\section{s0090 8.5 Microbiologically influenced corrosion mechanisms}

p0390 The role of microorganisms in metal corrosion is known since the first part of the 20th century. Since then, hundreds of publications appeared that are dedicated to understanding what happens when microorganisms are present and how can we explain the mechanisms of the metal deterioration.

p0395 Several mechanisms responsible for MIC have been proposed because of its complexity [46]. Some suggested MIC mechanisms will be explained in more details in the following sections.

\section{s0095 8.5.1 Cathodic depolarization by hydrogenase}

p0400 A depolarization of the cathodes through oxidation of the hydrogen evolved on the cathode is summarized as follows [47]:

\begin{tabular}{|l|l|}
\hline Anodic reaction & $4 \mathrm{Fe} \rightarrow 4 \mathrm{Fe}^{2+}+8 \mathrm{e}^{-}$ \\
Water dissociation & $8 \mathrm{H}_{2} \mathrm{O} \rightarrow 8 \mathrm{H}^{+}+8 \mathrm{OH}^{-}$ \\
Cathodic reaction & $8 \mathrm{H}^{+}+8 \mathrm{e}^{-} \rightarrow 4 \mathrm{H}_{2}$ \\
Hydrogen oxidation & $\mathrm{SO}_{4}^{2-}+4 \mathrm{H}_{2} \rightarrow \mathrm{H}_{2} \mathrm{~S}+2 \mathrm{H}_{2} \mathrm{O}+2 \mathrm{OH}^{-}$ \\
Precipitation & $\mathrm{Fe}^{2+}+\mathrm{H}_{2} \mathrm{~S} \rightarrow \mathrm{FeS}+2 \mathrm{H}^{+}$ \\
Precipitation & $3 \mathrm{Fe}^{2+}+6 \mathrm{OH}^{-} \rightarrow 3 \mathrm{Fe}(\mathrm{OH})_{2}$ \\
The overall reaction & $4 \mathrm{Fe}+\mathrm{SO}_{4}^{2-}+4 \mathrm{H}_{2} \mathrm{O} \rightarrow \mathrm{FeS}+3 \mathrm{Fe}(\mathrm{OH})_{2}+2 \mathrm{OH}^{-}$ \\
\hline
\end{tabular}

p0405 This theory is also valid for other metals such as aluminum alloys [48]. Problems arose when it turned out that there were some Desulfovibrios (like the hydrogenasenegative Desulfotomaculum orientis), which cannot depolarize the cathode, whereas the hydrogenase-positive D. desulfuricans could [49]. Da Silva and his coworkers formulated a new mechanism of cathodic depolarization [50]. Other researchers demonstrated the effect of FeS in the cathodic depolarization [51-53]. 
p0410 Bryant et al. described another important observation that the corrosion rate depends largely on the total activity of hydrogenase within the biofilm, rather on the bacterial population size [51]. In spite of numerous publications, several important factors were not considered in the classical depolarization theory, such as the following [52]:

o0040 1. effect of sulfide, bisulfide, and hydrogen sulfide produced from the sulfate reduction in the anodic reactions;

o0045 2. effect of hydrogen sulfide on the cathodic reaction;

o0050 3. effect of elemental sulfur from the biotic or abiotic oxidation of sulfur;

o0055 4. fluctuation in the environmental conditions between anaerobic and aerobic conditions; and

00060 5. production of other corrosive metabolites.

\section{s0100 8.5.2 King and Miller mechanism}

p0440 This mechanism theory, proposed by King and Miller in 1971, states that the iron sulfide produced by the SRB and the iron pipe material produced a galvanic cell, caused by localized corrosion, that also contributed to the rate of corrosion [53]. The proposed mechanism theory indicated that depolarization was caused by the iron sulfide rather than the SRB. Hydrogen would be adsorbed onto FeS rather than Fe, and electrons transferred to the $\mathrm{FeS}$ would depolarize the atomic hydrogen into molecular hydrogen, therefore allowing the SRB to use it via hydrogenase. Thus, by linking the $\mathrm{Fe} / \mathrm{FeS}$ electrochemical reaction as the main mechanism for SRB corrosion, King and Miller evaded the issue of hydrogenase's ineffectiveness with regard to atomic hydrogen. In addition to avoiding the issue with hydrogenase, the main reaction in this mechanism is the electrochemical reaction, which operates at equal ratio for $\mathrm{Fe}$ and $\mathrm{FeS}$. In the King and Miller mechanism, the role of SRB was primarily to enable the regeneration of $\mathrm{FeS}$, rather than the cathodic reaction itself.

\section{s0105 8.5.3 The anodic depolarization mechanism}

p0445 The anodic depolarization mechanism was first mentioned in 1981 [54]. The results of extensive investigations are as the follows:

\begin{tabular}{|l|l|}
\hline Anodic reaction & $4 \mathrm{Fe} \rightarrow 4 \mathrm{Fe}^{2+}+8 \mathrm{e}^{-}$ \\
Water dissociation & $8 \mathrm{H}_{2} \mathrm{O} \rightarrow 8 \mathrm{H}^{+}+8 \mathrm{OH}^{-}$ \\
Cathodic reaction & $8 \mathrm{H}^{+}+8 \mathrm{e}^{-} \rightarrow 4 \mathrm{H}_{2}$ \\
Anodic depolarization & $3 \mathrm{Fe}^{2+}+6 \mathrm{OH}^{-} \rightarrow 3 \mathrm{Fe}(\mathrm{OH})_{2}$ \\
Hydrogen oxidation & $\mathrm{SO}_{4}^{2-}+4 \mathrm{H}_{2} \rightarrow \mathrm{H}_{2} \mathrm{~S}+2 \mathrm{H}_{2} \mathrm{O}+2 \mathrm{OH}^{-}$ \\
Dissociation of hydrogen sulfide & $\mathrm{H}_{2} \mathrm{~S} \rightarrow \mathrm{S}^{2-}+2 \mathrm{H}^{+}$ \\
Anodic depolarization & $\mathrm{Fe}^{2+}+\mathrm{S}^{2-} \rightarrow \mathrm{FeS}$ \\
The overall reaction & $4 \mathrm{Fe}+\mathrm{SO}_{4}^{2-}+4 \mathrm{H}_{2} \mathrm{O} \rightarrow \mathrm{FeS}+3 \mathrm{Fe}(\mathrm{OH})_{2}+2 \mathrm{OH}^{-}$ \\
\hline
\end{tabular}


p0450 According to these reactions, the corrosion of iron goes through electron generation in metal dissolution reaction, and the $\mathrm{H}^{+}$ions are formed in dissociation of water. After formation of $\mathrm{H}_{2}$ (the name of this step is "cathodic polarization") the $\mathrm{H}_{2}$ forms a layer and protects the metal surface. The main corrosion product is $\mathrm{Fe}(\mathrm{OH})_{2}$. Then the sulfate-reducer bacteria convert the $\mathrm{SO}_{4}{ }^{2-}$ to $\mathrm{H}_{2} \mathrm{~S}$ and after its reaction with iron ions, the formation of $\mathrm{FeS}$ depolarizes the anode.

\section{s0110 8.5.4 Other mechanisms}

p0455 There are some other proposed mechanisms. One of them based on sulfide describes the importance of the biomineralization in MIC [55]. The so-called three-stage mechanism elaborated by Romero [56], proposes a three-step reaction, which determines the metal deterioration.

p0460 Recently appeared the biocatalytic cathodic sulfate reduction (BCSR) theory, which is based on bioenergetics [57]. This theory explains through the activity of sulfatereducer bacteria (which is the most dangerous one from the point of view of MIC) why and when they attack metals. The theory states that an SRB biofilm on a steel surface needs energy for its growth or maintenance. When there is a lack of electron donors (e.g., a lack of organic carbon due to diffusional limitation), the sessile cells at the bottom of an SRB biofilm will switch to elemental iron as an alternate electron donor for the oxidation of sulfate in its energy production. On the other hand, these cells may use the elemental iron simply because they are abundantly available nearby. The following equations can be used to explain the bioelectrochemistry in BCSR. In the SRB attack against carbon steel, in the anodic reaction, iron is oxidized, which releases electrons, while the cathodic reaction is sulfate reduction utilizing these electrons.

\begin{tabular}{|l|l|}
\hline $\begin{array}{l}\text { Anode } \\
\text { Cathode }\end{array}$ & $\begin{array}{l}4 \mathrm{Fe} \rightarrow 4 \mathrm{Fe}^{2+}+8 \mathrm{e}^{-} \text {(iron dissolution) } \\
\mathrm{SO}_{4}^{2-}+8 \mathrm{H}^{+}+8 \mathrm{e}^{-} \rightarrow \mathrm{HS}^{-}+\mathrm{OH}^{-}+3 \mathrm{H}_{2} \mathrm{O}(\mathrm{BCSR})\end{array}$ \\
\hline
\end{tabular}

p0465 Cathodic reaction shows the half reaction of sulfate reduction catalyzed by the biofilm.

p0470 Generally, the rate of anodic and cathodic reactions is equivalent and determines the overall MIC rate.

\section{s0115 8.6 Consequences of MIC in the gas and oil industry}

\section{s0120 8.6.1 Degradation and deterioration}

p0475 In previous parts of the chapter, the most important criterion and appearance of the MIC were discussed. Now we shall see how this type of corrosion appears in the oil and gas industry. 
(a)

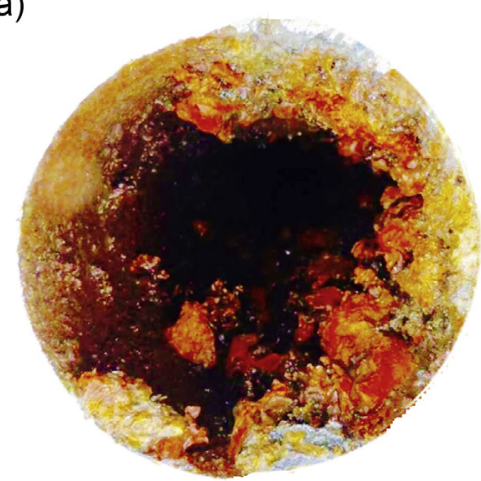

(b)

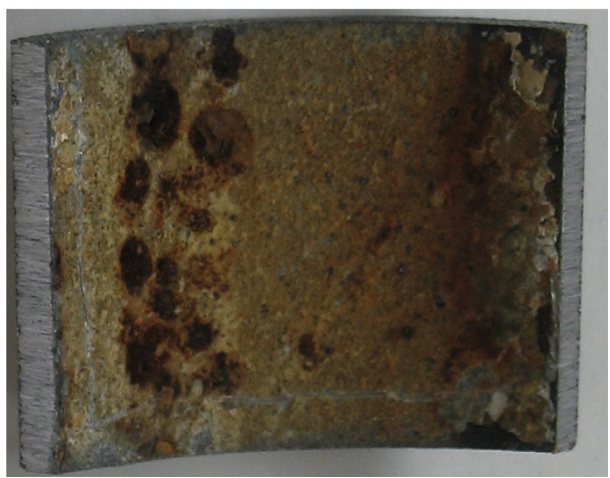

f0030 Figure 8.5 Internal corrosion of a pipeline caused by microbiologically influenced corrosion. (a) Internal clogging of pipeline, (b) local attacks on the inner surface of a pipeline.

p0480 MIC is a well-known and an ongoing problem in oil and gas production and transmission sectors. Fig. 8.5(a) and (b) show typical damage caused by MIC in pipelines.

p0485 When speaking about bacterial activity in oil, diesel, and naphtha, it refers to the microbial degradation of oil and its products as well as to the MIC in pipelines (up- and downstream pipes, fill-pipe sump, transporting pipelines), tankers, etc. In the degradation, five hydrocarbon-degrading bacteria are involved; they represent strains of two classified species. The degradation of petroleum products is important because hydrocarbons act as an excellent food source for a wide variety of microorganisms [58-60]. The biodegradation and corrosion studies revealed that these Bacilli degrade the $\left(\mathrm{CH}_{2}-\mathrm{CH}_{2}\right)_{\mathrm{n}}$ to $\left(\mathrm{R}-\mathrm{CH}_{3}\right)$ in oil and diesel and are capable to oxidize ferrous/manganese into oxides. Microbial activity leads to unacceptable level of turbidity, corrosion of pipeline, and souring of stored products. The corrosionrelevant microorganisms are the same that were discussed in Section 8.2 of this chapter. Their activity is influenced by the presence of nutrient and the proper temperature.

p0495 Table 8.1 summarizes the problems that could arise because of MIC in oil and gas production, transportation and storage conditions.

p0500 Crude, gas, and water injection pipelines are subjected to different types of corrosion, one of which is MIC that results from accelerated deterioration triggered by different microbial activities existing in hydrocarbon systems. The effect of fluid flow on MIC of pipeline steel is confirmed because MIC has been detected not only in static fluid systems but also in flow systems. The structure and material properties of biofilms were influenced by the fluid flow and had a significant effect on MIC corrosion rates of metals such as carbon steels [61].

p0505 In most existing wells, oil flow contains fluctuating quantity of water, which is crucial to the microbial existence. Oil flow rates affect the biofilm adherence to the surface. For SRB, moderate flow rates $(0.1-0.5 \mathrm{~m} / \mathrm{s})$ have been shown to change 
t0010 Table 8.1 List of damages in the oil and gas industries, and the associated microorganisms

\begin{tabular}{|l|l|}
\hline Damages & Microorganisms associated \\
\hline Sludge accumulation & $\begin{array}{c}\text { Several, different } \\
\text { microorganisms } \\
\text { Polymer-producing bacteria, } \\
\text { fungi } \\
\text { Anaerobe microorganisms, fungi }\end{array}$ \\
$\begin{array}{l}\text { Microbiologically influenced corrosion in storage } \\
\text { tanks }\end{array}$ & $\begin{array}{l}\text { Several microorganisms } \\
\text { Suspended solids in the oil } \\
\text { Biodegradation of hydrocarbons } \\
\text { Injectors biofouling } \\
\text { Sulfur accumulation } \\
\text { Breakage of engine parts }\end{array}$ \\
\hline
\end{tabular}

SRB biofilm morphology, increase biofilm rigidity, and produce shear stress. At sufficiently high flow rates $(\geq 3.5 \mathrm{~m} / \mathrm{s})$, SRB adhesion and biofilm growth are inhibited [61]. Studies conducted by British Petroleum indicated that at flow velocities higher than $5 \mathrm{~m} / \mathrm{s}$, microbes cannot adhere to the pipeline inner wall. On the other hand, if some microorganisms were attached to the metal surface, high turbulent flows boost the transport of nutrients for microbes and remove the metabolic products, thus enhancing the multiplication and exopolymeric substance production. All these conditions augment the biofilm thickness under which corrosion reactions are initiated. When the biofilm is already dense, a very fast stream can wash down the upper part of the film.

p0510 In the presence of oxygen the most corrosive anaerobic microbes (the sulfate reducers) do not show active life, but we have to remember that they live together in a community of aerobic microorganisms and there exist synergistic interactions among each other, i.e., oxygen consumption enhances the aerobic microbial life and makes the environment favorable for the anaerobic microorganisms. In crude pipelines, MIC is conventionally attributed to three species of bacteria, namely SRB and total general bacteria [among them are several others, direct (acid producers) and indirect (methanogen) corrosion relevant microorganisms], which are influenced by the fluid flow conditions. Pipelines transporting brackish subsurface water are subject to frequent corrosion, failures (partly electrochemical, chemical, and microbial types) despite the addition of oxygen scavengers (sodium bisulfite).

p0515 Microbial activity in oil reservoirs is well known. The low-molecular weight components are hydrolyzed by methanogenic consortia to methane and $\mathrm{CO}_{2}$, while 
transforming light oil to heavy oil and to bitumen. The presence of sulfate in injection water assists SRB to produce sulfide. Addition of nitrate encourages competition by stimulating nitrate-reducing bacteria with concomitant reduction in activity of SRB. Removing biogenic sulfide is important, because it contributes to pitting corrosion and the result is a pipeline failure.

p0520 Experience has shown that effective management of the MIC threat is, for operators, often more elusive and problematic than the control of other internal corrosion threats. The mitigation of the MIC in the oil and gas industry needs well-trained specialists, such as corrosion engineers, oilfield microbiologists, and scientists, to strengthen the ability to identify and manage microbial problems in all oilfield facilities.

\section{s0125 8.7 Knowledge gaps and future research trends}

p0525 This section looks closer on ways to account for knowledge gaps in the field of MIC detection, evaluation, monitoring, and control.

p0530 MIC is a nonlinear process with respect to time. Before recognizable corrosion due to MIC becomes apparent, there is an initial period in which microbial populations undergo changes and the chemical and physical properties of the metal surface alter considerably. The nonlinearity of MIC presents a substantial problem for the corrosion engineers trying to forecast the operational life of structures. Although the basics of MIC processes (as previously discussed) are quite understood, various knowledge gaps remain.

p0535 There exist several gaps between research and applications in the oil and gas fields. The following sections capture some of these gaps.

\section{s0130 8.7.1 Knowledge and acquaintance deficiency}

p0540 In many cases, MIC is referred to as "catchall" process because of its complex association with corrosion processes where other corrosion mechanisms were discarded. Furthermore, a clear understanding of the initiation and mechanism of MIC does not exist because fundamental research of MIC lags behind applied research, which is only aimed at diagnosing or solving a particular problem. A common misunderstanding among managers is that biofilms should be completely eliminated, an unmanageable and, arguably, pointless request. To enlighten and change this kind of thinking from biofilm removal to improved biofilm formation control, it is indispensable to better appreciate the complex abiotic and biotic interface interactions taking place between the metal surface and the liquid phase (mainly water). In addition, the majority of MIC subject matter experts (including microbiologists, chemists, inspectors, regulators, metallurgists) belong to diverse scientific communities, with little interaction. Data sharing from those outside the MIC research community, which may include potential crossover qualification strategies from biofilm researchers, is infrequent.

p0545 The efforts to further shrink the gap between research and applications in the oil and gas industry can be classified into the areas listed under the following topics. 


\section{s0135 8.7.2 Sampling procedures and evaluation methodologies}

p0550 Generally, sampling procedures gather information on operating parameters, corrosion rates, and microbiological conditions over an identified time period so that any tendencies in the outcome results can be identified and interpreted. Because of normal statistical variations related to field-collected samples and subsequent microbiological testing, more reliable data can be obtained from performing tests on samples collected over a range of time other than single time sample collection. For instance, samples of bulk fluids from pipelines are often collected to detect and quantify levels of planktonic (dynamic) microbes. To ensure that test results are relevant to MIC, data from bulk fluids should be interrelated with other pipeline data, including liquid composition, operational conditions, sessile (attached) microbes' counts, and corrosion data.

p0555 Recent improvements in investigative methodologies (analytical, microbiological, electrochemical, and microscopy techniques) and instrumentation have made MIC evaluations, both at the laboratory and field locations, more reliable. Using microsensors to perform local chemical analysis within the biofilm is one of the most exciting advances in instrumentation.

p0560 Other noteworthy research tools for the study of biofilm structure are the following:

u0110 - Fiber-optic microprobe (optrode) for locating the biofilm-bulk water interface,

u0115 - Scanning vibrating electrode microprobe, where a highly capacitance-sensitive microelectrode scans over a metal surface (pipeline) exposed to an electrolyte and detects potential differences between anodic and cathodic sites. Current density in pitting areas is recorded, and thus cathodic and anodic areas are mapped. The current density maps can be overlapped with images of the surface attained through the microscope.

p0575 Modern instruments such as confocal laser scanning microscopy, environmental scanning electron microscope, quartz crystal microbalance with dissipation mode, and AFM allow nondestructive real-time monitoring of biofilms.

p0580 Studies of microbial species present in oil and gas pipelines have conventionally depended on the use of samples attained from pipelines to grow bacterial cultures in the laboratory. Laboratory results cannot accurately simulate the actual environments and operating conditions in assets such as pumps, pipelines, fittings, reservoirs. Therefore lab culture-dependent approaches misjudge the biocomplexity of microbial communities in biofilms. To overcome the shortcomings of the lab culture-dependent techniques, many culture-independent molecular microbiology techniques (see Chapter 22 of this book) have been developed in the past decades and introduced to oil and gas industry.

\section{s0140 8.7.2.1 Microbiology: existence versus influence}

p0585 A major knowledge gap is, knowing "which kind of microbe is causing corrosion?" One of the objectives is to assess what is there and what they might be doing. It is worth mentioning that the activity of the microbes present within the biological system is more significant than its mere presence, i.e., just knowing "the microbial inhabitants" is not enough to understand the role of microbes in the biofilm. 
p0590 One crucial knowledge gap is the dynamics of microbial activity throughout the corrosion process. Until recently, techniques to identify and quantify microbial populations on corroding surfaces are mainly based on traditional techniques. Recent developments of microprobe analysis techniques will allow the chemical makeup of the corroding surface to be investigated. Fluorescence in-situ hybridization technique allows direct quantification of specific types of bacteria in microbial populations without the need to culture the cells in growth media. Enzymatic techniques provide opportunities to establish proper models to simulate microbial influenced corrosion and evaluate the behavior of metallic materials in liquids.

p0595 The utilization of special tools to identify microbes, particularly non-cultivationbased molecular tools, such as quantitative real-time polymerase chain reaction and high-throughput $16 \mathrm{~S} / 18 \mathrm{~S}$ ribosomal DNA sequencing, is considered to be an important advancement in understanding the roles of different microbes associated with MIC (see Chapter 22 of this book). These non-cultivation-based molecular tools offer the potential to:

u0120 - identify dominant bacteria in a given biological environment regardless of the limitations of standard counting procedures;

u0125 - determine the fraction of MIC-causing bacteria in the entire microbe's population;

u0130 - pinpoint bacteria that are vulnerable or resilient to antimicrobial biocides;

u0135 - assess the variations in the overall microbes population caused either by the use of inhibitors (biocides) or nutrient alterations; and

u0140 - accomplish more reliable sampling methods that are not affected by time or transport concerns.

\section{s0145 8.7.2.2 Detection and monitoring}

p0625 Detection and monitoring methods are the most crucial tools in the field of MIC. Diagnosing MIC requires a wide range of field and laboratory analyses that may take time to complete. In addition, there is a strong tendency to require other mechanisms of corrosion to be disproved before MIC is diagnosed and mitigated, which lengthens the process.

p0630 Detection methods are mainly focused on the application and implementation of biological methods by making use of the features of the MIC-related bacteria. Monitoring programs for MIC have focused mainly on the assessment of planktonic populations in water samples and general corrosion by using corrosion coupons or online probes such as linear polarization resistance or electrical resistance probes. However, there exist disadvantages and doubts surrounding this kind of monitoring procedures, such as that the planktonic populations do not accurately reflect the types and numbers of organisms living in biofilms and affecting biodeterioration complications.

p0635 Additionally, the susceptibility of planktonic microorganisms to antimicrobial additives significantly differs from that of sessile organisms within the biofilm, mainly because of the protective action of their EPS.

p0640 Monitoring methods must provide information on well-established biofilms. The detection and monitoring data could be used to support development of procedures that would allow for improved prediction and modeling, because much of the industries use different approaches for collection of MIC-relevant data. 


\section{s0150 8.7.2.3 Procedures and standardization}

p0645 Practical procedures and standards, such as standard corrosion test coupons and MICrelevant standard microbial communities, are desired. These procedures and standards could be employed to achieve reliable and comparable cross-laboratories investigations. Data from such investigations can then be utilized in common databases that assist in understanding of what differentiates MIC from other forms of corrosion. It is also important to implement the results in appropriate testing standards and specifications.

\section{s0155 8.7.2.4 Modeling and prediction}

p0650 There are classes of microbes that are known to have a substantial influence (e.g., APB, SRB) on metals and materials in the oil and gas systems, but the relationship between these microbes and other microorganisms in a mixed or contaminated system is poorly understood. That is why modeling is needed to identify the role microbes play in MIC. Understanding the metabolic procedures that rule the development and persistence of microbes in oil and gas environments and/or in contact with infrastructure materials will permit the development of effective qualification tactics through the control of microbes' metabolism mechanism or inhibiting the MICcausing agents.

p0655 Mathematical models can positively influence predicting the impact and necessity for biocide deployment as a method to limit MIC. Models need to exhibit mechanical and chemical interactions between diverse microbes present in complex biofilms formed on metals. These interactions have been problematic and difficult to measure and assess.

\section{s0160 8.7.2.5 Future research significances}

p0660 MIC researchers can perform an active role in materials, methods, procedures, and standards advancement and improvement in the direction of comprehensive understanding and recognition of MIC mechanisms. The research priorities can be listed as follows:

u0145 - Material-microbe interaction. To focus and identify changes microbes make on metals and their alloys.

u0150 - Intermicrobes' interactions. To investigate and determine which of the microbes present in the biofilm are active, mixed complex systems with multiple microbes should be examined to learn how these microbes can interact with each other.

u0155 - Development of standards. Standard test methods are required to guarantee that cases and accounts of MIC are being classified correctly. Collection of field samples should be of top importance for standards' development.

p0680 In the future, to overcome the difficulties caused by MIC, specialists from different fields need to work together to develop effective strategies against microbial degradation such as MIC. 


\section{s0165 8.8 Conclusions}

p0685 The main types of bacteria associated with MIC in oil and gas industry are sulfate reducers (SRB), iron reducers (IRB), and iron and manganese oxidizers (IOB, MOB). Among the anaerobes the SRB with the subgroup Desulfovibrios are the most dangerous, but the aerobic $P$. aeruginosa, which is one of the aerobic slime-forming bacteria, also cause severe corrosion of steel structures. Other microbes, i.e., acid producers, also deteriorate metals surfaces with fast metal dissolution. The planktonic cells are less dangerous than the sessile microbes embedded in biofilms.

p0690 The excretion of exopolymeric substances, which "glue" microbes onto solid surfaces, facilitates the biofilm formation. Bacterial surface and medium characteristics play important role in the microbial transfer rate, adhesion, and resulting biofilm size. A mature biofilm, which is a matrix of water, microorganisms, and organic and inorganic matter, provides an environment for anaerobes and for their metabolism near the solid surface. Such conditions favor the growth of SRB. These microorganisms produce sulfide ions from sulfate ions, which react with iron or other metal ions, forming insoluble metal sulfide. Localized corrosion starts underneath biofilms by establishing corrosion cells with very low-levels or negligible oxygen contents and low local $\mathrm{pH}$ values. These conditions favor the growth of SRB.

p0695 On the other hand, aerobic microorganisms (not only slime formers but also others such as acid producers) are far from the solid surface, i.e., near the top of the biofilm. Those microbes, by consuming the sulfide ions (metabolites of anaerobes), produce sulfuric acid and sulfate ions and evolve hydrogen. This postulated mechanism relates to the outer surface of vessels and structures. The environment within a pipeline is quite different. The biofilm and the aggressive metabolites alter the electrochemical reactions, change the $\mathrm{pH}$ values, and induce reactions at the cathodes and anodes. All these reactions that are enhanced by the presence of microorganisms increase the deterioration of crude- and gas-handling facilities through MIC.

p0700 Typical characteristic of MIC is a shiny, blackish surface and round pits scattered all over the solid surface, which in time cause the perforation of the metal. MIC is mainly prevalent underneath biofilms; the probability of biofouling is proportional to the risk of MIC. The mechanisms of MIC based on bacteria-metal reactions facilitated by microorganism also form an important part of the chapter.

p0705 After understanding the phenomenon and importance of MIC, it is important to learn as much as possible about the potential for MIC attack and circumstances/conditions (metals, microbial communities, $\mathrm{pH}$, and temperature) that could lead to such attack. The first is to have a profound look at the local injury. For example, a slime or blackish shiny layer covering the metal surface could indicate MIC attack. The next step is proper pigging of the pipeline and sampling for identification of microorganisms in the collected organic-, inorganic- and biodeposits. When unambiguous is the presence of corrosion relevant microorganisms, the diagnosis is MIC, which often goes hand-inhand with other types of corrosion and, additionally, with scaling. To decrease the influence of corrosion-relevant microorganisms, it needs the active collaboration of specialists from different fields (metallurgists, engineers, microbiologists) as only this cooperative activity will bear fruit in the future. 


\section{References}

[1] A.R. Al-Shamari, A.W. Al-Mithin, S. Prakash, M. Islam, A.J. Biedermann, A. Methew, Some empirical observation about bacteria proliferation and corrosion damage morphology in Kuwait oilfield waters, in: NACE CORROSION 2013, 2013. Paper No. 2748.

[2] B.J. Little, J.S. Lee, Microbiologically influenced corrosion: an update, International Materials Reviews 59 (7) (2014) 384-393.

[3] M. Urquidi-Macdonald, A. Tewari, H.L.F. Ayala, A Neuro-Fuzzy knowledge-based model for the risk assessment of microbiologically influenced corrosion in crude oil pipelines, Corrosion 70 (11) (2014) 1157-1166.

[4] B.J. Little, J.S. Lee, Microbiologically Influenced Corrosion, Wiley Series in Corrosion, John Wiley \& Sons, Inc., Hoboken, New Jersey, 2007.

[5] R. Bhola, S.M. Bhola, B. Mishra, D.L. Olson, Microbiologically influenced corrosion and its mitigation: a review, Material, Science Research India 7 (2) (2010) 407-412.

[6] R. Javaherdashtri, Microbiologically Influenced Corrosion: An Engineering Insight, Springer, London, 2008.

[7] T. Siddique, T. Penner, J. Klassen, C. Nesbo, J.M. Foght, Microbial communities involved in methane production from hydrocarbons in oil sands tailings, Environmental Science and Technology 46 (17) (2012) 9802-9810.

[8] C.G. Struchtemeyer, J.P. Davis, M.S. Elshahed, Influence of the drilling mud formulation process on the bacterial communities in thermogenic natural gas wells of the Barnett Shale, Applied and Environmental Microbiology 77 (14) (2011) 4744-4753.

[9] M. Kermani, D. Harrop, The impact of corrosion on oil and gas industry, SPE Production and Facilities 11 (03) (1996). SPE-29784-PA.

[10] N. Youssef, M. Elshahed, M. McInerney, Microbial processes in oil fields: culprits, problems, and opportunities, Advances in Applied Microbiology 66 (2009) 141-251.

[11] D. Enning, J. Garrelfs, Corrosion of iron by sulfate-reducing bacteria: new views of an old problem, Applied and Environmental Microbiology 80 (4) (2014) 1226-1236.

[12] M. Bethencourt, F. Botana, M. Cano, Biocorrosion of carbon steel alloys by an hydrogenotrophic sulfate-reducing bacterium, Desulfovibrio capillatus isolated from a Mexican oil field separator, Corrosion Science 48 (2006) 2417-2431.

[13] J.P. Euzéby, List of bacterial names with standing in nomenclature, a folder available on the internet, International Journal of Systematic Bacteriology 47 (1997) 590-592.

[14] E.S. Bastin, F.E. Greer, C.A. Merritt, G. Moulton, The presence of sulfate-reducing bacteria in oil field waters, Science 63 (1926) 21-24.

[15] B.J. Little, P. Wagner, F. Mansfeld, An overview of microbiologically influenced corrosion, Electrochimica Acta 37 (12) (1992) 2185-2194.

[16] E. Valencia-Cantero, J.J. Peña-Cabriales, Effects of iron-reducing bacteria on carbon steel corrosion induced by thermophilic sulfate-reducing consortia, Journal of Microbiology and Biotechnology 24 (2) (2014) 280-286.

[17] G. Muyzer, A.J. Stams, The ecology and biotechnology of sulphate-reducing bacteria, Nature Reviews Microbiology 6 (2008) 441-454.

[18] W. Allan Hamilton, Sulphate-reducing bacteria and the offshore oil industry, Trends in Biotechnology 1 (2) (1983) 36-40.

[19] S. Kebbouche-Gana, M.L. Gana, Biocorrosion of carbon steel by a nitrate-utilizing consortium of sulfate-reducing bacteria obtained from an Algerian oil field, Annals of Microbiology 62 (1) (2012) 203-210. 
[20] C. Hubert, M. Nemati, G. Jenneman, G. Voordouw, Corrosion risk associated with microbial souring control using nitrate or nitrite, Applied Microbiology and Biotechnology 68 (2) (2005) 272-282.

[21] I. Neria-González, E.T. Wang, F.R. Rez, J.M. Romero, C.H. Rodriguez, Characterization of bacterial community associated to biofilms of corroded oil pipelines from the southeast of Mexico, Anaerobe 12 (3) (2006) 122-133.

[22] C.S. Chan, S.C. Fakra, D. Emerson, E.J. Fleming, K.J. Edwards, Lithographic ironoxidizing bacteria produce organic stalks to control mineral growth: implications for biosignature formation, The ISME Journal 5 (2011) 717-727.

[23] R. Winston Revie (Ed.), Uhlig's Corrosion Handbook, third ed., John Wiley \& Sons Inc., 2011.

[24] I. Beech, Corrosion of technical materials in the presence of biofilms - current understanding and state-of-the art methods of study, International Biodeterioration and Biodegradation 53 (3) (2004) 177-183.

[25] H. Mansouri, S.A. Alavi, A study of microbial influenced corrosion in oil and gas industry, Conference Paper, in: The 1st International Conference of Oil, Gas, Petrochemicals and Power Plants, 2012, pp. 15-27. Teheran.

[26] B. Huber, B. Herzog, J.E. Drewes, K. Koch, E. Müller, Characterization of sulfur oxidizing bacteria related to biogenic sulfuric acid corrosion in sludge digesters, BMC Microbiology 16 (153) (2016) 1-11.

[27] G.C. Friedrich, D. Rother, F. Bardischewsky, A. Quentmeier, J. Fischer, Oxidation of reduced inorganic sulfur compounds by bacteria: emergence of a common mechanism? Applied and Environmental Microbiology 67 (7) (2001) 2873-2882.

[28] D. Pokorna, J. Zabranska, Sulfur-oxidizing bacteria in environmental technology, Biotechnology Advances 33 (6 Pt 2) (2015) 1246-1259.

[29] M. Pósfai, R.E. Dunin-Borkowski, Sulfides in biosystems, Reviews in Mineralogy and Geochemistry 61 (2006) 679-714.

[30] M. Magot, Indigenous microbial communities in oil fields, in: B. Ollivier, M. Magot (Eds.), Petroleum Microbiology, ASM Press, Washington, DC, 2005, pp. 21-33.

[31] B.J. Little, F.B. Mansfeld, P.J. Arps, J.C. Earthman, Microbiologically influenced corrosion, in: Encyclopedia of Electrochemistry, Wiley-VCH Verlag GmbH \& Co., 2007.

[32] ASM International, Corrosion in the petrochemical industry, in: V. Burt (Ed.), Essential Research, second ed., ASM International, 2015, p. 426.

[33] Boundless Microbiology, 2016. Retrieved from: https://www.boundless.com/microbiology/ textbooks/boundless-microbiology-textbook/introduction-to-microbiology-1/microbes-andthe-world-19/classification-of-microorganisms-208-1908/.

[34] R. Eckert, T.L. Skovhus, Using molecular microbiological methods to investigate MIC in the oil and gas industry, Materials Performance 50 (8) (2011) 50-54.

[35] G. Leer, G.D. Lewis (Eds.), Microbial Biofilms: Current Research and Applications, Caister Academic Press, New Zealand, 2012.

[36] S.W. Borenstein, Microbiologically influenced corrosion handbook, in: Woodhead Publishing Series in Metals and Surface Engineering, Woodhead Publishing, Cambridge, UK, 1994.

[37] J. Telegdi, Microbiologically influenced corrosion (Chapter 6), in: K. Demadis (Ed.), Water Treatment Processes, Nova Science Publisher, 2012, pp. 145-167.

[38] J. Telegdi, T. Szabó, F. Al-Taher, É. Pfeifer, E. Kuzmann, A. Vértes, Coatings against corrosion and microbial adhesion, Materials and Corrosion 61 (12) (2010) 1001-1007.

[39] J. Telegdi, L. Románszki, F. Al-Taher, E. Pfeifer, E. Kálmán, Nanolayers against microbial adhesion, in: NACE International Corrosion, 2009. Paper No. 3987. 
[40] G. Diósi, J. Telegdi, G. Farkas, L.G. Gazsó, E. Bokori, Corrosion influenced by biofilms during wet nuclear waste storage, International Biodeterioration and Biodegradation 51 (2) (2003) 151-156.

[41] P. Gumpel, N. Arlt, J. Telegdi, D. Schiller, O. Moose, Microbiological influence on the electrochemical potential of stainless steel, Materials and Corrosion - Werkstoff und Korrosion 57 (2006) 715-723.

[42] J. Telegdi, A. Shaban, J. Beczner, Z. Keresztes, E. Kálmán, Biofilm formation controlled by quartz crystal nanobalance, Materials Science Forum 289-292 (1998) 77-82.

[43] B. El Gammudi, I. El Musrati, A. Bourgheya, A. El Tawil, Microscopic study of bacterial attachment on AISI 304 and AISI 316 stainless steel, Surfaces International Journal of Integrative Biology 4 (2) (2008) 72-77.

[44] B. Mishra, Corrosion characterization of advanced steels for use in the oil \& gas industry, International Journal of Metallurgical Engineering 2 (2) (2013) 221-229.

[45] J. Telegdi, L. Trif, L. Románszki, Smart antibiofouling composite coatings for naval applications (Chapter 9), in: M.F. Montemor (Ed.), Smart Composite Coatings and Membranes: Transport, Structural, Environmental and Energy Applications, Woodhead Publishing, 2016, pp. 123-155.

[46] S. Kakooei, M. Che Ismail, B. Ariwahjoedi, Mechanisms of microbiologiacally influenced corrosion. A review, World Applied Sciences Journal 17 (4) (2012) 524-531.

[47] C.A. Von Wolzogen Kühr, L.S. Van der Vlugt, Graphitization of cast iron as an electrochemical process in anaerobic soil, Water 18 (16) (1934) 147-165.

[48] W.P. Iverson, Direct evidence for the cathodic depolarization theory of bacterial corrosion, Science 151 (3713) (1966) 986.

[49] H. Cypionka, W. Dilling, Intracellular localization of the hydrogenase in Desulfotomaculum orientis, FEMS Microbiology Letters 36 (2-3) (1986) 257-260.

[50] S.D. Silva, R. Basséguy, A. Berger, The role of hydrogenases in the anaerobic microbiologically influenced corrosion of steels, Bioelectrochemistry 56 (1-2) (2002) 77-79.

[51] R.D. Bryant, W. Jansen, J. Boivin, E.J. Laishley, J.W. Costerton, Effect of hydrogenase and mixed sulfate-reducing bacterial populations on the corrosion of steel, Applied and Environmental Microbiology 57 (10) (1991) 2804-2809.

[52] P. Marcus, Corrosion mechanism in theory and practice, in: P. Marcus (Ed.), Corrosion Technology Series, third ed., CRC Press, 2011.

[53] R.A. King, J.D.A. Miller, Corrosion by sulfate reducing bacteria, Nature 233 (1971) 491-492.

[54] C. Obuekwe, D. Westlake, J. Plambeck, Corrosion of mild steel in cultures of ferric iron reducing bacterium isolated from crude oil: II. Mechanism of anodic depolarization, Corrosion 3711 (1981) 632-637.

[55] B. Little, P. Wagner, K. Hart, R. Ray, D. Lavoie, K. Nealson, C. Aguilar, The role of biomineralization of microbiologically influenced corrosion, Biodegradation 9 (1) (1998) $1-10$.

[56] M. de Romero, The mechanism of SRB action In MIC based on sulfide corrosion and iron sulfide corrosion products, in: Corrosion/2005, NACE international, Houston, TX, (2005), 2005. No. 05481.

[57] T. Gu, D. Xu, Why are some microbes corrosive and some not?, in: CORROSION'2013, Orlando, FL, March (2013), 2013, pp. 17-21. Paper No. C2013-0002336.

[58] A. Rajasekar, S. Ponmariappan, S. Maruthamuthu, N. Palaniswamy, Bacterial degradation and corrosion of naphta in transporting pipeline, Current Microbiology 55 (5) (2007) $374-381$. 
[59] F. Bruecker, B.C. Santos, P.D. Quadros, Fuel biodegradation and molecular characterization of microbial biofilms in stored diesel/biodiesel blend B10 and the effect of biocide, International Biodeterioration and Biodegradation 95 (2014) 346-355.

[60] S. Mohanan, A. Rajasekar, N. Muthukumar, et al., The role of fungi on diesel degradation, and their influence on corrosion of API 5LX, Corrosion Prevention and Control 52 (4) (2005) 123-130.

[61] J. Wen, T. Gu, S. Nesic, Investigation of the Effect of Fluid Flow on SRB Biofilm, in: Corrosion/2007, NACE International, Houston, TX, (2007), 2007. Paper No. 07516. 


\title{
Non-Print Items
}

\begin{abstract}
Microbiologically influenced corrosion (MIC) refers to the influence of microorganisms on the kinetics of corrosion processes of metals and nonmetallic materials, caused by adhering to the interfaces (usually referred to as "biofilms"). The corrosionrelevant microbes like to attach to solids via exopolymeric substances (EPS), which give the main component of the slime and form biofilms at the solid-liquid interface. Not only single stains but also diverse bacterial communities (e.g., iron and manganese and sulfur oxidizers and reducers, slime formers, acid producers, etc.) are able to produce biofilm. There are gradients of microorganisms, oxygen concentrations, and $\mathrm{pH}$ values inside the biofilm, which consists mostly of water, microbial metabolites, exopolymeric substances, organic, and inorganic molecules of the aqueous environment. Beneath this biofilm, corrosion initiates and progresses resulting in localized corrosion that can lead, if remained uncontrolled, to pinholes and leaks. This chapter discusses the different microbes responsible for MIC in oil and gas industry, classification of microorganisms, MIC mechanisms, and biofilm development and factors necessary for its formation. Finally the chapter briefly discusses current knowledge gaps in understanding and managing MIC and future research and engineering trends to close these gaps.
\end{abstract}

\section{Keywords:}

Biocorrosion, Biofilm, Microbes in gas and oil industry, Microbiologically influenced corrosion. 